\title{
Sí MISMO COMO PUEBLO: COMUNIDAD EN EL PENSAMIENTO DE M. HeIDEgGER
}

Daniel Michelow Briones ${ }^{1}$

\begin{abstract}
Resumen: El presente análisis tiene como objetivo una descripción sintética pero acabada del fenómeno de la alteridad en el pensamiento de M. Heidegger, abocandose primero al tratamiento doble que se le da a esta en Ser y tiempo como otredad y comunidad, así como al posterior desarrollo y profundización que experimenta en los ańos 30 de la mano del concepto de pueblo. Dos preguntas centrales guían el presente escrito: la primera es aquella por la necesidad metódica que determina al pueblo como la forma más amplia posible de la comunidad humana y la segunda aquella que busca determinar en que grado es el Volk una comunidad caracterizada por una verdadera apertura al Otro.
\end{abstract}

Palabras Clave: Sí-mismo. Alteridad. Comunidad. Pueblo. Heidegger.

\section{INTRODUCCION: COMUNIDAD Y OTREDAD: LA ALTERIDAD EN SER Y TIEMPO}

Las fuertes repercusiones de la obra de Martin Heidegger en el siglo XX y aún hoy en día se explican en gran parte debido a las implicaciones políticas que algunos de los temas centrales de su pensamiento conllevan, más precisamente, como ciertas ideas de su proyecto se entrelazan con el violento acontecer del siglo pasado. El presente análisis se abocará al modo en que el pensador de la selva negra aborda el tema de la alteridad. Esta, como problema filosófico, está presente desde los escritos de juventud de Heidegger hasta su obra tardía con idéntica fuerza, sin embargo, se hace evidente que el modo de

\footnotetext{
${ }^{1}$ Instituto de Filosofía Universidad Católica de Chile, Santiago - Chile. Pesquisa con el financiamiento de ANID-Fondecyt, con el proyecto 3180019 de Postdoctorado. (D) https://orcid.org/0000-00027927-5626. E-mail: daniel.michelow@gmail.com.
}

https://doi.org/10.1590/0101-3173.2021.v44n4.09.p105

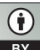


acercamiento a ella está en constante cambio, tomando incluso la forma de una elaboración del fenómeno del pueblo.

Ya en su obra principal, Ser y tiempo (ST), trata Heidegger con un fenómeno de la alteridad complejo, que se presenta a través de dos frentes. El primer frente es aquel desarrollado principalmente en los $\$ \$ 26$ y 27 de la primera sección de la obra. Esta primera modalidad de la alteridad es expresada a través de conceptos tales como coestar (Mitsein), coexistencia (Mitdasein), el uno (das Man) y los otros (die Anderen). ${ }^{2}$ El tratamiento de dicha modalidad de la alteridad tiene el sentido principal de construir una estructura de relación entre la propia existencia y la de los otros, pero de tal modo que se ponga a resguardo al Dasein de una perdidad de sí mismo (Selbstverlorenheit) (HEIDEGGER, GA 2, p. 116), expresada, precisamente, en el uno y los otros, en los que el Dasein no está ya vuelto hacia sí mismo. Esta autoreferencia no tiene lugar como una negación del otro, sino que, más bien, como una peculiar convivencia con él, en la cual se le deja en libertad ${ }^{3}$ para que comparezca desde sus particulares proyectos en el mundo, esto es, desde su propio sí-mismo. A tal modalidad de la alteridad, para efectos de una clara diferenciación, se le ha otorgado, en el contexto del presente análisis, el título otredad. ${ }^{4}$

Expresado sintéticamente, se da en la otredad una relación en la que se resguarda tanto la propia existencia, así como, subsecuentemente, la existencia del otro, asegurándose un cierto modo de convivencia que está determinado por el carácter absoluto de las partes. El mundo es "[...] desde siempre el que yo comparto con los otros [...] un mundo en común [Mitwelt]” (HEIDEGGER,

2 Todas las traducciones de los términos empleados por Heidegger en ST provienen de la versión de Jorge Eduardo Rivera. Las citas, sin embargo, indican el origen en la Gesamtausgabe (GA).

${ }^{3}$ Esta comprensión de la libertad, vale decir, del coestar y la coexistencia como dejar libre es descrita por Heidegger del siguiente modo: "Pero -se dirá- la expresión 'Dasein' muestra con claridad que este ente 'por lo pronto' es irrespectivo a otros, aunque sin duda también pueda estar ulteriormente 'con' otros. Sin embargo, no debe pasarse por alto que empleamos el término 'coexistencia' para designar aquel ser con vistas al cual los otros son dejados en libertad dentro del mundo. Esta coexistencia de los otros queda intramundanamente abierta para un Dasein y así también para los coexistentes, tan sólo porque el Dasein es en sí mismo esencialmente coestar [Mitsein].” (HEIDEGGER, GA 2, p. 122).

${ }^{4}$ Las modalidades de la alteridad en ST que aquí se designan otredad y comunidad han sido anteriormente tratadas en detalle en un artículo de mi autoría del año 2019. Ahí se asevera que "[...] desde mi siempre propio ocuparme en el mundo libero al otro en su ser, y soy a la vez liberado en mi ser como coexistencia para el otro, pero la condición de posibilidad de mi poder-ser no se pone en juego en esta liberación, más que en el sentido de ser remitido a mí mismo como la condición de posibilidad de la libertad del otro. Comparezco para el otro como una coexistencia en su propio proyecto. Liberar entonces no significa circunscribir el ser del otro, o el mío propio, en ámbitos de posibilidad distintos que el de la relación al propio ser, sino que exclusivamente significa atestiguar al otro en su ser." (MICHELOW, 2019, p. 158) 
GA 2, p. 118), pero donde compartir -cuando es auténtico- no debe ser entendido como una disposición de la existencia en la que su constitutivo aislamiento (Vereinzelung) se pierda.

Las críticas de la literatura especializada al concepto de alteridad en $S T$ se dirigen principalmente a la otredad y apuntan específicamente a una suerte de insuficiencia en la elaboración del coestar respecto de la relación del propio ser y el de los otros, en el sentido de que el acto de liberación -así como se ha descrito-, no da nunca pie a una articulación propiamente comunitaria, sino que más bien a un mero dejar comparecer ${ }^{5}$. En cuanto a la primera recepción de esta obra, podemos mencionar ejemplificadoramente la crítica de H. Arendt, que afirma que el coestar estará siempre limitado por el carácter absoluto del sí-mismo y su consecuente ensimismamiento ${ }^{6}$, así como la de E. Levinas (2016, p. 67), que declara a Heidegger un continuador de una tradición filosófica que opera "[...] una reducción de lo Otro al Mismo." Este tipo de críticas, en distintas variaciones, fue repetida en las décadas siguientes, específicamente bajo la forma de la búsqueda de reconocimiento (Anerkennung) del otro. Dicha búsqueda tiene lugar principalmente en una tradición de carácter hermenéutico y podemos contar en ella nombres tales como Gadamer, Ricoeur, Taylor, Habermas, Apel, Vattimo, solo por nombrar a algunos. ${ }^{7}$

Pero en los últimos años, debido quizás a la enorme variedad de posiciones desde la que se ha ejercido la crítica, tiende nuevamente la discusión a centrarse más bien en la oportunidad, es decir, en determinar si, en general, es apropiado exigirle a la metódica heideggeriana tal reconocimiento -en el que se acepte, como lo plantea Gadamer, al otro como el fundamento del

\footnotetext{
${ }^{5} \mathrm{La}$ estructura de liberación a la que aquí se hace referencia y que es objeto de crítica no debe nunca confundirse con una suerte de cosificación del otro. Heidegger expresamente aclara que "el estar vuelto a otros es sin duda ontológicamente diferente del estar vuelto a las cosas que están-ahí. El 'otro' ente tiene, él mismo, el modo de ser del Dasein. En el estar con otros y vuelto hacia otros hay, según esto, una relación de ser de Dasein a Dasein.” (HEIDEGGER, GA 2, p. 124). La crítica se centra en la capacidad y alcance del dejar libre para poder ejercer como fundamento para una estructura de relación que sobrepase la singularidad del Dasein.

${ }^{6}$ Arendt (2005, p. 221) asevera que “[...] el carácter más esencial de este sí-mismo es su absoluto ensimismamiento, su radical separación de los que son sus iguales. A fin de conseguirlo se introdujo como existenciario el precursar la propia muerte; pues con ello el hombre hace realidad el principium individuationis absoluto. Únicamente el precursar la propia muerte le arranca de la trama con los que son sus iguales, y que en la forma del 'se' le impiden siempre ser él-mismo."

7 Gadamer (Verdad y Método. Salamanca: Sígueme, 1977), Ricoeur (Caminos de reconocimiento. Madrid: Trotta, 2005), Taylor (El multiculturalismo y la 'politica del reconocimiento'. México: FCE, 1993.), Habermas (La Inclusión del otro. Barcelona: Paidós, 1999.), Apel (La transformación de la filosofía. Madrid: Taurus, 1985.), Vattimo (Creer que se cree. Barcelona: Paidós, 1996.).
} 
conocimiento de la propia finitud, es decir de una experiencia fundamental del propio ser que uno no puede darse a mí mismo ${ }^{8}$ - o si ya, de antemano, se contravienen con esto los fundamentos de la analítica del Dasein, pues, parece ser claro, que a través de esta modificación de la alteridad se afectaría el dictum fundamental de la facticidad de la existencia, es decir, su autoreferencialidad expresada como ser-cada-vez-mío (Jemeinigkeit). En este sentido, contravenir la autoreferencia de la existencia, del sí-mismo, implicaría, precisamente agravar el problema que se pretende solucionar, desactivando los dispositivos que posibilitan cualquier encuentro con el otro. A este respecto y desde de este tipo de recepción de tipo metodológica, que considera dicha modificación inoportuna, dice A. Vigo (2014, p. 333):

Pues lo que Heidegger tiene primariamente en vista aquí es aquella dimensión de autocomparecencia esencialmente ejecutiva y autoreferencial, en la cual el Dasein, al decidir por sí mismo, se hace cargo auténticamente de sí, y hace así justicia a la exigencia de autotrasparencia que le impone su propio ser. En esta verdad de la existencia [...] reside pues la condición última de posibilidad de todo encuentro genuino del Dasein consigo mismo y con los otros.

Ambas posiciones, tanto aquella de la recepción primera y su consiguiente desarrollo hermenéutico, como la metodológica ${ }^{9}$, que apunta a permanecer dentro de los límites del método dado, coinciden, fundamentalmente, en que en la elaboración de sus posiciones se pasa por alto el hecho de que es el propio Heidegger, quien considera que la alteridad no se agota en el tratamiento que se le da en la primera sección de $S T$.

Es necesario preguntar entonces, cuál es el requerimiento que emana desde la segunda sección de $S T$. La respuesta es en primera instancia evidente: aquello que se busca es un sí-mismo común, que deberá expresarse bajo el

${ }^{8}$ Gadamer (2001, p. 438) apunta: "[...] la apertura hacia el otro implica, pues, el reconocimiento de que debo estar dispuesto a dejar valer en mí algo contra mí, aunque no haya ningún otro que lo vaya a hacer valer contra mí."

9 J. J. Garrido (2018, p. 195) ańade en una investigación reciente -que se puede situar dentro del tipo metodológico de recepción- lo siguiente: "Pues bien, la solicitud, la cual es una estructura que constituye la condición de posibilidad de todo acto con los otros, cuando se da propiamente, esto es, cuando deviene autorreferencial, permitiendo la apertura del Dasein en sí-mismo, viene rasgada por un carácter 'anticipativo liberador' [verspringend-befreienden], el cual tiene lugar como acto ligado a la misma anticipación existencial del Dasein, en tanto tener-que-ser y ser-en-cada-caso-mío. Lo que se anticipa, desde esta modalidad excelsa de solicitud es un 'salto anticipativo frente al otro' [Vorausspringen dem Anderen gegenüber] bajo la finalidad ineluctable de devolverle al otro lo que está siempre ya a su cuidado como lo que, justamente, está a su cuidado, sin más." 
controvertido termino pueblo (Volk). En vistas a lo anteriormente expuesto, vale decir al ser-cada-vez-mío como rasgo fundamental de la existencia fáctica del Dasein, se vuelve, sin embargo, esta respuesta oscura y paradójica. Esto quiere decir, por lo pronto, que la otredad no agota todas las posibilidades de la alteridad, ni, por otro lado, logra subsanar por sí misma los problemas que desde esta se plantean.

La orientación hacia el resguardo de la existencia vuelta hacia sí misma y la exacerbación del aislamiento y distanciamiento de los otros, que es propia de la otredad, se vuelven en el tratamiento que da Heidegger a la segunda modalidad de la alteridad en $S T$ difusa. Dicha modalidad aparece solo en la segunda sección de la obra, principalmente en el $\$ 74$. El recinto conceptual en el cual es expresada la alteridad como comunidad es el de pueblo, destino común (Geschick), lucha (Kampf) y generación (Generation) entre otros. A dicha modalidad se le ha llamado, en el contexto de la presente investigación, comunidad.

Pero, ¿qué se asevera cuando se afirma que la literatura especializada pasa por alto el requerimiento de la segunda sección de ST? Evidentemente no se quiere decir que el tema no sea considerado en lo absoluto o que haya sido tratado deficientemente. Más bien, que el punto de partida para todo tratamiento del Volk ha sido, insistentemente, la comprensión de este existencial como una estructura derivada y subsecuente del coestar, a saber cómo la forma más eminente de su autenticidad. ${ }^{10}$

El tratamiento específico de los modos como el pueblo es derivado del coestar en los distintos tipos de recepciones queda fuera de los límites de esta investigación. Aun así, someramente, se puede apuntar que, aún en las más diversas variaciones, es posible hallar la tendencia hacia una interpretación en la que el momento determinante para la estructura de relación entre coestar y pueblo está dada por el aparente vacío en $S T$ en la elaboración de un coestar propio, opuesto al uno, en el sentido descrito en el marco de la solicitud anticipativo liberadora (vorspringend-befreiende Fürsorge), en la que

\footnotetext{
${ }^{10}$ Esto pasa, por ejemplo, en Barash quien asevera que "[...] es cierto que Heidegger proporciona extensas descripciones de la dimensión inauténtica de las colectividades humanas vinculadas por 'la mismidad de los otros' y de la búsqueda inauténtica de una suspensión de la finitud de la existencia. Sin embargo, cuando se trata de identificar la colectividad que encarne esa autenticidad, solo sugiere una mera descripción en términos de la 'gestación' del Dasein del 'pueblo'(Volk).” (p. 291). Este presupuesto implica, como se describirá en detalle en las páginas siguientes, que el pueblo es él mismo una modalidad - la auténtica - y que, por tanto, no puede dar cabida a una forma inauténtica. Esto, en la práctica, ha obligado a la investigación especializada a explicar el fenómeno del pueblo inauténtico solo en términos políticos y no ontológicos, y por tanto insuficientes.
} 
se "[...] ayuda al otro a hacerse transparente en su cuidado y libre para él." (HEIDEGGER, GA 2, p. 122).

Aquello hacia lo cual se quiere llamar la atención aquí es si es esto lo que Heidegger ha pretendido al introducir el existencial del pueblo, vale decir, si el $\$ 74$ cumple de hecho la función en $S T$ de poner a disposición de la analítica existenciaria una respuesta concreta a la pregunta por el coestar autentico. Para resolver esta interrogante es necesario aclarar primeramente ciertas diferencias esenciales entre coestar y pueblo que pueden ser reveladas al rastrear la posibilidad concreta de un coestar autentico que se encuentra efectivamente - anunciada en ST. Nos referimos a la amistad. Esta forma del coestar está tratada de modo pasajero, sin embargo, suficientemente claro, para que valga a los propósitos argumentales del presente análisis:

El escuchar a alguien [das Hören auf...] es el existencial estar abierto al otro, propio del Dasein en cuanto coestar. El escuchar constituye incluso la primaria y auténtica apertura del Dasein a su poder-ser más propio, como un escuchar de la voz del amigo que todo Dasein lleva consigo. El Dasein escucha porque comprende. Como comprensor estar-en-el-mundo con los otros el Dasein está sujeto, en su escuchar, a la coexistencia y a sí mismo, y en esta sujeción del escuchar [Hörigkeit] se hace solidario de los otros [ist zugehörig]. El escucharse unos a otros, en el que se configura el coestar, puede cobrar la forma de un "hacerle caso" al otro, de un estar de acuerdo con él, y los modos privativos del no querer-escuchar, del oponerse, obstinarse y dar la espalda. (HEIDEGGER, GA 2, p. 163).

La amistad es en este pasaje un ejemplo eminente de aquello que Heidegger entiende como forma autentica del coestar. Escuchar la voz del amigo no aleja, sino que más bien pone de modo aún más decidido al Dasein en dirección a su poder-ser, vale decir, en la amistad es él restituido a sí mismo. Esto es, tal como se describe el trato con el otro desde la solicitud anticipativo liberadora.

Escuchar la voz del amigo cumple antes el rol de un dispositivo de la individuación que uno de la pluralidad. El Dasein se refiere al otro, de modo tal que es resueltamente devuelto a sí mismo y solo por ello se pueden abrir posibilidades tales como hacer caso, estar de acuerdo u oponerse y dar la espalda -que Heidegger comprende como formas del tenerse a sí mismo-. Estas posibilidades solo pueden surgir desde la relación al otro que se plantea en la otredad. Como una participación exógena en el ámbito común, que puede ser considerada propia solo si pone al Dasein en la disposición hacia 
sí. En la amistad por tanto se da el tipo de relación que tiene la estructura previamente descrita: mutuamente liberadora para el propio proyecto. En la voz del amigo, por eso la llevamos con nosotros, resuena, cuando es honesta, el dictum de la existencia: en cada caso mío.

Se ha hecho hincapié en la amistad, pues en su descripción se vuelve evidente que el pueblo tiene un sentido distinto, que sobrepasa la estructura de la otredad. El pueblo es, así como lo ha planteado Heidegger, una relación en la que no prima la autoreferencia singularizadora ${ }^{11}$, sino que más bien la pertenencia a una suerte de horizonte existencial histórico en el que el símismo está disponible propiamente, solo una vez que el Dasein se vuelve hacia el otro constitutivamente. Por eso el planteamiento central del $\$ 74$ comienza su descripción como sigue:

Pero, si el Dasein destinal existe esencialmente, en cuanto estar-enel-mundo, coestando con otros, su acontecer es un co-acontecer, y queda determinado como destino común [Geschick]. Con este vocablo designamos el acontecer de la comunidad, del pueblo. El destino común no es el resultado de la suma de los destinos individuales, así como el convivir tampoco puede ser concebido como un estar-juntos de varios sujetos. (HEIDEGGER, GA 2, p. 384).

La diferencia respecto de cómo se ha elaborado en la primera sección la alteridad, de la mano del coestar es notoria. El pueblo, como se vuelve paulatinamente claro, no es la forma propia de la otredad y por tanto no puede ser comprendido como una estructura general bajo la cual el Dasein conviva con los otros y participe - exógenamente - desde una cierta y necesaria autoreferencia. Tampoco es una difusa excepción, que se permita, de tanto en tanto, a este estar vuelto hacia sí. Esto sería precisamente aquello que Heidegger ha llamado "la suma de destinos individuales" que en caso alguno puede ser comprendido como el "destino común" al que se hace referencia.

La elaboración de la comunidad como pueblo surge desde una recomprensión de la existencia del Dasein en la que la autoreferencia no es

\footnotetext{
${ }^{11}$ El carácter singularizador está en esta descripción acentuado porque en la comunidad se da la referencia a sí-mismo, pero en un contexto modificado. Un ejemplo de esto es el héroe, el que actúa desde una cierta autoreferencia y autotrasparencia que no puede ser entendida ya como un gesto de la individuación, sino que como un ponerse a disposición del acontecer histórico del pueblo. "La repetición propia de una posibilidad de existencia que ya ha sido - que el Dasein escoja su héroe-se funda existencialmente en la resolución precursora; porque en ella se hace por primera vez la opción que libera para el seguimiento combatiente y para la fidelidad a lo repetible.” (HEIDEGGER, GA 2, p. 385).
} 
desestimada, pero queda sujeta a los designios de un sí-mismo histórico y común. En el pueblo el auténtico hacerse cargo de la propia existencia es solo posible y depende de un cierto modo del convivir que va más allá de un mero dejar aparecer al otro. Pueblo no es para Heidegger por tanto una estructura subsecuente o una posibilidad que tenga lugar dentro del coestar. Pueblo no es el nivel óntico de la estructura ontológica coestar, sino que él es el coestar mismo en su totalidad. Expresado de otra forma, denomina el término Pueblo el modo de entendimiento del coestar y de todos sus momentos que surge desde el giro hermenéutico que caracteriza la segunda sección de $S T$. Es el modo que adopta el coestar en el momento en que la analítica del Dasein es retomada como análisis de la existencia histórica.

La comunidad del pueblo es posible dentro del contexto de $S T$ solo porque se ha abierto, en el tránsito entre la primera y la segunda sección de la obra, la posibilidad de acceso a una modalidad propia de la existencia del Dasein que no implica la pérdida del sí mismo cuando este no está autoreferido, que no es posible en ningún caso desde la otredad como momento central de la primera sección. La otredad, como expuesto, tiene sus propias formas de propiedad que son de origen esencialmente distinto a aquellas del pueblo. Esto nos lleva a las siguientes conclusiones: a) el pueblo no puede ser considerado por tanto un añadido a la primera sección en general, o más específicamente una subsecuencia de la otredad y b) subsumir estructuralmente pueblo al coestar nos impide ver en profundidad el giro entre la primera sección y la segunda de $S T$, que más allá del evidente tránsito entre fenomenología y hermenéutica, es una transformación de la relación entre mundo del sí mismo (Selbstwelt) y mundo común (Mitwelt). Esto se deduce del hecho de que la mirada hermenéutica y su tratamiento de la analítica del Dasein solo puede tener real asidero si la preeminencia o más bien agudizamiento (Zugespitzheit) que Heidegger había identificado ya en su obra temprana, del mundo del sí mismo ${ }^{12}$ - evidente en la otredad -, ha dado paso a un cierto balance entre estos dos tipos de acceso al mundo.

La solución ética a las deficiencias de la alteridad, en la que hace hincapié la primera recepción francesa de Heidegger, que posteriormente se transformará en la búsqueda de reconocimiento en la escuela hermenéutica, solo puede afectar a la alteridad como otredad porque, al igual que esta, está

12 "Se muestra que la vida fáctica puede ser vivida, experimentada y, en consecuencia, puede ser también comprendida históricamente desde un peculiar agudizamiento del mundo propio." (GA 58, p. 59-64, traducción propia). 
elaborada desde el agudizamiento del mundo propio. Así el problema del Volk permanece sin un tratamiento específico.

\section{AsPeCtos ESPECíficos SOBRE EL ACONTECIMIENTO DE LA COMUNIDAD COMO PUEBLO}

El paso siguiente en este análisis consiste en entregar una propuesta sustentable sobre el sentido de relación entre destino, generación, comunicación y lucha como momentos constitutivos del pueblo, tomando como punto de partida la tesis que se ha presentado, en la que pueblo es comprendido, no ya como una modalidad del coestar, sino que como el coestar mismo en su forma histórica. Si bien en el $\$ 74$ se delimita el recinto conceptual del existencial coestar en su sentido par como pueblo, no se encuentra en él un desarrollo acabado sobre el modo como sus estructuras se interrelacionan. Por esta razón será necesario recurrir a escritos de Heidegger de los años 30 en los que el tema es tratado de modo más amplio. El paso desde $S T$ a dichos textos posteriores implica una serie de problemas que se deberán describir en las siguientes páginas. El giro hermenéutico que se consagra en el $\$ 74$ es anticipado fugazmente en la primera sección en la que se asevera que:

El elementalmente, "acontece" siempre desde su futuro. En cada una de sus formas de ser y, por ende, también en la comprensión del ser que le es propia, el Dasein se ha ido familiarizando con y creciendo en una interpretación usual del existir Dasein "es" su pasado en la forma propia de su ser, ser que, dicho [Dasein]. Desde ella se comprende en forma inmediata y, dentro de ciertos límites, constantemente. Esta comprensión abre las posibilidades de su ser y las regula. Su propio pasado $-\mathrm{y}$ esto significa siempre el pasado de su "generación"- no va detrás del Dasein, sino que ya cada vez se le anticipa. (HEIDEGGER, GA 2, p. 20).

Esta anticipación y puesta en relación de la generación como estructura fundamental para el despliegue de la temporeidad (Zeitlichkeit) del Dasein no es casual. Heidegger considera que debe poner a disposición un elemento de tránsito entre el Dasein y el pueblo, pues la individuación conlleva el carácter constitutivo de la finitud (Endlichkeit) y el estar vuelto hacia la muerte (Sein zum Tode). El peculiar estar vuelto hacia los otros, tratado bajo el termino pueblo, o, expresado en términos figurativos, la pertenencia del Dasein al pueblo, no puede dar cabida a la pertenencia a un horizonte ilimitado, esto es, afáctico. Heidegger debe procurar una estructura horizontal que esté en 
una disposición temporal similar -sostenido por un mismo sentido fáctico de finitud- a la del Dasein descrita en la primera sección. "El pasado del Dasein es su generación" significa en términos inmediatos que el horizonte temporal común que presta la generación es uno que está constituido con miras a una finitud común o más específicamente: los coetáneos comparten las mismas vivencias concretas que remiten al estar vuelto o no hacia la muerte. Esto es, entonces, una indicación más de que el pueblo no puede ser tratado bajo la comprensión que lo propone como una forma concreta del coestar. Dicha función es, como señalado, la de la generación:

Conviviendo en el mismo mundo y resueltos a determinadas posibilidades, los destinos individuales ya han sido guiados de antemano. Sólo en el compartir y en la lucha queda libre el poder del destino común. El destinal destino común [das schicksalhafte Geschick] del Dasein en y con su "generación" es lo que constituye el acontecer pleno y propio del Dasein. (HEIDEGGER, GA 2, p. 385).

Esta frase de Heidegger quiere expresar la mutua pertenencia de ambos momentos: la generación se despliega en el acontecer del pueblo, pero en tal despliegue libera ella el poder de este último: esta co-pertenencia constituye la historicidad del Dasein. Si el acontecer del pueblo había sido caracterizado como destino común, es la generación ahora el destinal destino común (das schicksalhafte Geschick). Si el pueblo debe ser comprendido como el coestar en esta duplicidad de los existenciales, es la generación entonces el convivir (Miteinandersein). "La facticidad del convivir" (HEIDEGGER, GA 2, p. 121) es la facticidad de la generación y por tanto el modo finito a través del cual se abre el Dasein al coestar histórico. La generación en tanto convivir no es un mero coexistir o un "[...] simple estar-ahí de varios sujetos" (HEIDEGGER, GA 2, p. 121), sino que el "[...] compromiso común con una misma causa." (HEIDEGGER, GA 2, p. 122). Tal compromiso común con una misma causa tiene en la generación una estructuración precisa en la lucha y comunicación. ${ }^{13}$

Esta comunicación es el logos de la comunidad: la simple pero genuina irrupción en una palabra común de las posibilidades existenciales descubiertas en el convivir generacional como su proyecto. Para Heidegger, por tanto, solo en el contexto de la alteridad como pueblo es posible una palabra que irrumpa

\footnotetext{
${ }^{13}$ Rivera traduce Mitteilung como "compartir", mientras Gaos lo hace como "coparticipación". En ambos casos se aleja la interpretación del sentido común de la palabra "comunicación". Pareciera ser lo más ajustado insistir en este último término, evidentemente no como mera comunicación de información, sino como comunicación de posibilidades existenciales.
} 
en un ámbito común sin quedar ya por ello determinada como una habladuría (Gerede).

Junto a la comunicación aparece la lucha como momento estructural de la comunidad. Esta es comprendida en términos del pólemos (Пó $\lambda \varepsilon \mu \circ \varsigma$ ) heraclitiano. Heráclito anuncia que "Pólemos [la guerra] es el padre de todas las cosas y el rey de todas, y a unos los revela dioses, a los otros hombres, a los unos los hace libres, a los otros esclavos.” (p. 32) y aún más, "Es preciso saber que la guerra es común [a todos los seres], y la justicia es discordia, y todas las cosas se engendran por discordia y necesidad.” (p. 50). Heidegger (GA 40, p. 66) afirma:

La lucha, tal como se entiende aquí, es una lucha originaria; porque hace que los combatientes comiencen a surgir como tales; no es un simple arremeter contra algo ya existente. La lucha primeramente proyecta y desarrolla lo in-audito, lo hasta entonces no-dicho y lo im-pensado. Después serán los productores creadores, los poetas, pensadores y hombres de Estado los que sostendrán esta lucha.

Comunicación y lucha son el tejido estructural del convivir generacional, es lo que une a los unos con los otros y pone a disposición un sentido común de resolución respecto de la multiplicidad de posibilidades existenciales sobre las que la generación puede resolverse.

Dos elementos se pueden extraer de esta breve descripción de la dinámica y naturaleza de la generación. El primero es que la generación oficia como nexo entre el destino singular del Dasein y el destino común del pueblo. Sin embargo, el carácter de este nexo es aún oscuro. El segundo es que en esta descripción se hace referencia al fenómeno de generación, con la clara indicación en el correspondiente pie de página, que la comprensión guía sobre este fenómeno está dada por el trabajo de W. Dilthey. ${ }^{14}$ En este sentido y ante la falta de desarrollo concreto del tema en $S T$ se pueden permitir ciertas extrapolaciones, coherentes respecto de lo que se ha planteado en esta sección de la obra. Para Dilthey los movimientos del espíritu, vale decir, los logros intelectuales y el desarrollo científico han sido, equivocadamente, ordenados en un sistema cronológico exterior de meses, años y décadas, por lo que para entender cabalmente el curso de la historia es necesario buscar una unidad temporal que esté contenida precisamente en su propio curso (Verlauf). En este sentido se afirma que "[...] la

${ }^{14}$ El pie de página hace referencia a Über das Studium der Geschichte der Wissenschaften vom Menschen, der Gesellschaft und dem Staat, contenido en Obras Completas, tomo V (1924). 
generación es por lo pronto, como se ha mencionado, la denominación para un espacio de tiempo, a saber, una representación que entrega también una medida desde dentro, a la cual aquella de la vida humana está supeditada." (DILTHEY, p. 36). Que la vida humana esté supeditada a esta medida quiere decir que en su forma natural e inmediata es la vida misma la que entrega dicha unidad. Para entender la referencia que hace Heidegger al concepto diltheano de generación es necesario prestar especial atención a la descripción de esta como un "[...] un estrecho círculo de individuos, que están ligados hasta formar un todo homogéneo por la dependencia de los mismos grandes hechos y variaciones, que aparecieron en su época de receptividad a pesar de la diversidad de otros factores agregados". (DILTHEY, 1964, p. 61). Esta homogeneidad es la que presta el carácter fáctico a la generación y que pone a los coetáneos en la disposición común hacia su finitud. Es necesario hacer hincapié que la homogeneidad hermenéutica que plantea Dilthey no indica en ningún caso una suerte de indiferenciación en el interior de la generación. Más bien lo contrario: la generación se puede constituir solo como la tensión entre sus fuerzas internas, en la que se decide que posibilidades han de primar y cuales han de perderse. Por eso Dilthey (1964, p. 38) dice que "[...] así constituye una generación tal un todo, que es efectivo a través de la combinación variable de las condiciones para la producción de múltiples direcciones." Las generaciones están relacionadas como una totalidad continua (kontinuirliches Ganzes) de posibilidades que se heredan, desestiman o apropian y proyectan hacia la próxima generación. Heidegger entiende, por tanto, la generación como la unidad temporal finita del acontecer de un pueblo sin la cual la totalidad continua de este no puede ser entendida. Tal heredar, desestimar y proyectar son precisamente aquellos momentos que Heidegger trata bajo los términos repetición (Wiederholung) y respuesta (Erwiederung). Sin embargo, para Heidegger lo común de una generación queda sin explicación si no se lo piensa dentro del ámbito existencial que presta el pueblo. A diferencia de Dilthey, requiere el proyecto heideggeriano una estructura existencial que funde la condición de posibilidad para la estructura fáctica de la generación.

La tesis que indica que la comunidad del pueblo debe ser entendida como el coestar histórico de la comunidad y no como una posibilidad fundada en él desde la otredad, implica, precisamente, que el pueblo no debe ser entendido como una mera reproducción del Dasein individual en una versión grupal, sino que más bien como un horizonte histórico en el que se da un reordenamiento de los existenciales y de sus dinámicas internas. Esta reformulación existencial tiene formas precisas que toman fuerza en las conferencias dictadas por Heidegger en los años 30 y que por lo demás son 
aquellas que concentran la mayor cantidad de críticas políticas a su obra, pues ahí el acontecimiento del pueblo y el del tercer Reich quedan de un modo singular entrelazados. Las siguientes páginas se centrarán especialmente en el rol exacerbado que adquiere la espacialidad en la descripción y constitución del sí-mismo común.

\section{El PUEBLO, EL SUELO: UNA COMUNIDAD CERRADA}

El análisis anterior presta una sintética descripción del pueblo y sus momentos constitutivos en relación con el $\$ 74$ de $S T$. En los años 30 pretende Heidegger profundizar la descripción de la posibilidad de un sí-mismo colectivo a la luz de un aspecto anteriormente no tratado en profundidad sobre la relación entre historia y su específico tipo de espacialidad dada por el suelo $(\text { Boden })^{15}$. Esta relación es tratada expresamente en el seminario Lógica como la pregunta por la esencia del lenguaje (Lógica):

Los pueblos no entran en la historia como si esta fuera un espacio ya disponible, en el que ellos encuentran refugio, un derrotero dado de antemano que ellos solo tuviesen que transitar, sino que "hacer historia" significa: crear primeramente espacio y suelo. (HEIDEGGER, GA 38, p. $85) \cdot{ }^{16}$

La relación entre pueblo y suelo como fundamento para la constitución de la historicidad propia ha sido tratada por Heidegger en los ańos 20 solo tangencialmente y sin alcanzar el rol central que se le quiere otorgar en la década siguiente. Esta relación es para Heidegger determinante en su intento de llevar a cabo una descripción del pueblo que obedezca a la pregunta doble, en primer término, por la configuración interna de sus modalidades, vale decir por su propiedad e impropiedad y, en segundo término, por los limites exteriores de la comunidad, esto es, por el estatus existencial de otro tipo de comunidades.

Evidente es que la primera dimensión de la pregunta planteada adquiere su forma concreta en la relación entre el pueblo alemán y el pueblo

\footnotetext{
${ }^{15}$ Esta relación es pasajeramente nombrada en ST, pero no tratada expresamente: "La tradición desarraiga tan hondamente la historicidad del Dasein, que éste no se moverá ya sino en función del interés por la variedad de posibles tipos, corrientes y puntos de vista del filosofar en las más lejanas y extrañas culturas, y buscará encubrir bajo este interés la propia falta de fundamento (Bodenlosigkeit)." (HEIDEGGER, GA 2, p. 21).
}

${ }^{16}$ Todas las traducciones de Lógica son propias. 
judío. El pueblo como lo ha planteado Heidegger en $S T$, en tanto que comunidad existencial, pero aún sin entablar la relación expresa al suelo, no permite discriminar entre la propiedad e impropiedad de su acontecer. La diferencia entre alemanes y judíos no radica para Heidegger en su calificación como pueblo en general, ni en su incidencia en la historia, sino que en el arraigo al suelo. Solo desde tal arraigo sería posible para un pueblo acceder a un futuro primordial y su ámbito de preguntas propio. Evidentemente suelo no es para Heidegger un mero territorio geográfico, sino que eminentemente el estar enclavado en un cierto ámbito histórico ${ }^{17}$. Heidegger (GA 96, p. 46) describe el despliegue del pueblo judío a la luz de un marcado antisemitismo ontohistórico ${ }^{18}$ del siguiente modo:

El temporal aumento del poder del judaísmo tiene su fundamento en que la metafísica de Occidente, especialmente en su desarrollo en la modernidad, ofreció el punto de partida para el expandirse [Sichbreitmachen] de una, por lo demás, racionalidad vacía y de una capacidad de cálculo, y que por tales medios adquirió albergue en el - espíritu, sin ser capaz de comprender por sí mismo los ámbitos [Bezirke] ocultos de decisión. Mientras más originarias y más primordiales sean las decisiones futuras y las preguntas, más inaccesibles siguen siendo ellas al — odio.

Este aumento de poder y consiguiente albergue en el espíritu de una racionalidad vista como vacía y su capacidad de cálculo es para Heidegger precisamente la forma propia del pueblo sin suelo, y que por tanto no puede en su expansión, sino que operar contra "[...] el arraigamiento de la existencia histórica.” (HEIDEGGER, GA 40, p. 43). La utilización de las palabras espíritu y expansión en este contexto son clara señal del intento de Heidegger de distinguir la incidencia histórica del pueblo impropio de la historicidad verdadera del pueblo arraigado, vale decir de su hacer historia. Hacer historia es entonces para Heidegger una tarea que solo se puede llevar a cabo desde un suelo, pues aquello que adolece de suelo es solo una humanidad ahistórica y desvinculada. Tal pueblo, tal humanidad desvinculada, construye y se adentra también en su propia historia, pero dicha historia no es la originaria y primordial del ser, sino que precisamente aquella en que esta es ocultada por la actitud calculante. Evidentemente el desarraigo no se manifiesta para

\footnotetext{
${ }^{17}$ A estas alturas es evidente que no es posible explicar el fenómeno de suelo a través de la nación o de la raza. El suelo heideggeriano no se deja reducir a estos, sin embargo, parece aceptarlos sin problema como consecuencias necesarias.

${ }^{18}$ El termino se debe a P. Trawney. Véase: Heidegger (2014).
} 
este modo de despliegue de la pregunta por la comunidad exclusivamente en el pueblo judío, sino que también en todo pueblo que no esté en una disposición reverencial hacia su propia herencia y pertenencia, y por tanto carente de historicidad.

Para la segunda dimensión de la pregunta sigue Heidegger la misma estructura argumentativa que se ha descrito recién, pero no se dirige ya a las modalidades del pueblo, sino que a los limites posibles de lo comunitario, al estatus existencial posible de otras formas de comunidad. Así plantea Heidegger su rechazo contra toda forma de comunidad que sobrepase los límites del pueblo como -ejemplificadoramente- aquella idea de humanidad en tanto que comunidad transnacional planteada por Jaspers. ${ }^{19}$ Esta comunidad transnacional o, en general, este tipo de comunidad máxima adolece para Heidegger de una universalidad impropia y ahistórica que funda solo en un afán racionalista. Dicha transnacionalidad impide, para Heidegger, de antemano toda posibilidad para el coestar histórico verdadero y toda relación al ser. Es, en último término, una quimera o comunidad imposible. Toda otra comunidad que no sea aquella del pueblo basa su estructura en una colectividad de individuos. Heidegger plantea en este sentido en Lógica que la pregunta por el hombre en términos del "quién", esto es, en vistas del pueblo, es una fundamentalmente distinta de aquella que pregunta por un individuo, por un yo y en última instancia por una colectividad de yoes:

Hasta ahora en la filosofía al preguntar por el Yo no se ha tenido en cuenta el verdadero Yo individual. Se ha preguntado por el Yo en general, por la consciencia en general, se ha querido eludir lo individual. Por el contrario, debemos Nosotros preguntar por nosotros mismos, por nuestra propia esencia. ¿No significa esto llevar la Yoidad, el egoísmo al extremo? ¡Nosotros nos hacemos con la pregunta "¿quién somos Nosotros mismos?" al mismo tiempo el centro de la total, real y posible humanidad! (HEIDEGGER, GA 39, p. 46).

No ya más la pregunta por qué es el hombre, sino por quién somos nosotros mismos se vuelve central y pone en relación originaria al hombre y al pueblo en la descripción völkisch que implementa Heidegger y que pretende fundar una identidad histórica. La pregunta por el hombre y por la humanidad

\footnotetext{
${ }^{19}$ Jaspers (2016, p. 65-66, traducción propia) indica que "[...] la universidad es siempre, cuando es real, expresión de un pueblo. Ella busca la verdad, ella quiere conocer lo universalmente válido, ella quiere servir a la humanidad, representar al género humano sin más. Humanitas -incluso cuando este concepto se ha transformado muchas veces y profundamente- le pertenece a su esencia. Por eso es justamente cada universidad una nacional que pertenece a un pueblo, pero ella aspira más allá precisamente comprender lo supranacional y volverlo real."
} 
puede ser de este modo solo fructífera en términos de revertir la caída desde lo primordial solo si en su centro está instalada esta muy específica comprensión ontológica de pueblo, su suelo y su historia.

\section{Pueblo: Alteridad del otro Como sí mismo}

En la primera parte del presente artículo se delineó la diferencia entre otredad y comunidad como formas de la alteridad. Se ha descrito a su vez que la alteridad como otredad pone a disposición una estructura de relación exógena, esto es, constituida por la dinámica de un dejar ser al otro en su proyecto existencial, su sí-mismo, pero de tal modo que ese dejar ser no resulte nunca en una dinámica de mutua constitución. La primacía existencial sigue estando dada por la individualización. Incluso en casos en que esta dinámica es experimentada en su forma más profunda, como en la amistad, se trata de un modo eminente de apertura al propio poder-ser o, en otros términos, una relación en la que cada uno está vuelto hacia sí.

La alteridad como comunidad, esto es, como pueblo, se presenta en primera instancia en ST como una posibilidad existencial diferente pues implica una relación con el otro que no está determinada de antemano por un estar referido hacia sí como un ente singular. Sin embargo, cuando esta comunidad existencial es trabajada por Heidegger en los años treinta se vuelve claro que en el pueblo no se forma una comunidad con el otro en cuanto tal, sino que en cuanto sí-mismo. Se trata en este sentido de un sí-mismo ampliado que no tiene su límite en el ente singularizado que cada uno es. La inclusión del suelo y la historicidad como estructuras determinantes del pueblo tienen, para Heidegger, como objetivo que el paso entre otredad y comunidad no se transforme en una apertura indiscriminada hacia los otros, sino que más bien en la ampliación del radio de constitución del sí-mismo. La pregunta repetida incontables veces en Lógica “quiénes somos nosotros mismos?” opera como el fundamento de la reelaboración, no ya de la relación sin resguardos entre sí-mismo y otro, sino que del desplazamiento de la frontera que divide a ambos. En la comunidad no se da tampoco una relación de mutua constitución con el otro, sino que la incorporación del sí-mismo singular en ámbitos más amplios de despliegue en los que el otro no es ni incorporado, ni desaparece, sino que es forzado al repliegue. Si en el caso de la otredad es el Dasein singular que aparece en el mundo propio o que nos permite aparecer en el suyo aquel con el que se entabla la relación exógena descrita, en la comunidad el pueblo se construye 
una identidad völkisch para ejercer la misma distancia inabarcable hacia los otros pueblos. En Heidegger domina un miedo reverencial a la apertura a lo externo, esto es al otro en tanto otro, que se manifiesta en sus posiciones política absolutistas y en último término en un antimodernismo a ultranza. La añoranza de una antigüedad dorada de comunidades intimas que domina su pensamiento, implica que toda adecuación de aquello que constituye la identidad histórica debe ser llevada a cabo bajo una dinámica de oposición al otro y por tanto no cabe que los destinos planetarios puedan ser enfrentados por un esfuerzo común de los pueblos, sino que a través el ascenso de un pueblo que los domine o guie a todos. Solo se puede entablar esta relación de comunidad, la del pueblo, con quien se comparte ya de antemano la misma identidad histórica. El pueblo de Heidegger funciona bajo la dinámica de la comunidad homologada que no permite rasgos de pluralidad. Todo cambio es visto como parte de la caída de la humanidad y nunca como una oportunidad para esta. Esto, quizás, porque su pensamiento parece estar vuelto hacia el pasado, a la raíz y su herencia de tal modo que solo es propio aquel futuro que se dispone únicamente como un duplicado de lo que ha sido y por tanto es todo camino nuevo por el que transite la historia un ocultamiento del ser. La comprensión de la historia que propone Heidegger parece ponernos así, paradójicamente, siempre en una relación negativa hacia todo despliegue histórico. Será necesario preguntarnos entonces si esta disposición hacia la historia y su comunidad será capaz de prestar un fundamento fructífero desde el cual podamos asumir los enormes retos que nos plantea nuestra propia época y aquellas por venir o si por el contrario este pueblo y su acontecer son finalmente formas de evasión ante lo urgente.

MICHELOW, D. B. Self as a people: community in the Thought of M. Heidegger. Trans/form/ação, Marília, v. 44, n. 4, p. 79-100, Out./Dez., 2021.

\begin{abstract}
The present analysis aims at a synthetic but finished description of the phenomenon of alterity in M. Heidegger's thought, first addressing the double treatment that is given to this in Being and time as otherness and community, as well as the subsequent development and deepening that it experienced in the 1930s hand in hand with the concept of people. Two central questions guide this writing: the first is that due to the methodical necessity that determines the people as the broadest possible form of the human community and the second one that seeks to determine to what degree the Volk is a community characterized by a true openness to the Other.
\end{abstract}

Keywords: Self. Alterity. Community. People. Heidegger. 


\section{REFERENCIAS}

ARENDT, H. Ensayos de comprensión 1930 - 1954. Madrid: Caparrós, 2005.

BARASH, J. Martin Heidegger desde la perspectiva del siglo XX: Reflexiones sobre la Gesamtausgabe de Heidegger. Revista de Filosofía Universidad Complutense, Madrid, v. 7, n. 11, p. 275-303, 1994.

DILTHEY, W. Die geistige Welt: Einleitung in die Philosophie des Lebens. Erste Hälfte (GS 5). Göttingen: Vandenhoeck \& Ruprecht, 1964.

GADAMER, H-G. Verdad y método I. Salamanca: Sígueme, 2001.

GARRIDO, J. J. La pregunta por el quién del ser-con: Heidegger en su Ser y Tiempo. SEMINARIO DE HISTORIA DE LA FILOSOFÍA, Madrid, 2018. Anales [...], v. 36, n. 1, p. 175-200, 2018.

HEIDEGGER, M. (GA 58). Grundprobleme der Phänomenologie (WS 1919/20). Frankfurt a. M.: Vittorio Klostermann, 1992.

HEIDEGGER, M. (GA 2). Sein und Zeit. Frankfurt a. M.: Vittorio Klostermann, 2018. En espańol: Traducido por Jorge Eduardo Rivera. Santiago: Universitaria, 1997.

HEIDEGGER, M. (GA 96). Überlegungen C. Frankfurt a. M.: Vittorio Klostermann, 2014.

HEIDEGGER, M. (GA 38). Logik als die Frage nach dem Wesen der Sprache (SS 1934). Frankfurt a. M.: Vittorio Klostermann, 2020a.

HEIDEGGER, M. (GA 40). Einführung in die Metaphysik. Frankfurt a. M.: Vittorio Klostermann, 2020b.

HERÁCLITO. Fragmentos. Mexico D.F.: Archivo Digital de Humanidades Ervin Said, 2020.

JASPERS, K. Schriften zur Universitätsidee. I. Werke, Ban 21. Basel: Schwabe, 2016. LÉVINAS, E. Totalidad e infinito. Salamanca: Sígueme, 2016.

MICHELOW, D. Otredad y comunidad en 'Ser y Tiempo': dos experiencias fundamentales del mundo reveladas en el fenómeno de la alteridad. Hybris, Santiago, v. 10, n. 1, p. 147-167, 2019.

VIGO, A. Arqueologia y aleteiologia: Estudios heideggerianos. Berlin: Logos, 2014.

Recebido: 03/12/2020

Aceito: 03/3/2021 